\title{
DIVERSE ANATOMICAL CONFIGURATION OF ILIOINGUINAL NERVE IN RELATION TO LATERAL FEMORAL CUTANEOUS NERVE
}

\author{
Khizer H. A. Mookane, Azra M. Karnul \\ Department of Anatomy, MVJ Medical College \& Research Hospital, Bangalore, Karnataka, \\ India \\ Department of Anatomy, East Point College of Medical Sciences and Research Centre, \\ Bangalore, Karnataka, India
}

\begin{abstract}
The variability in the formation of llioinguinal nerve has been documented in the literature especially related to iliohypogastric nerve. But so far very few cadaveric studies have been documented on variation in the branches of ilioinguinal nerve. A case presented which demonstrates aberrancy of its anatomic position. Although the course of ilioinguinal nerve is well known, nostudies have documented the variation of its course in relation to lateral femoral cutaneous nerve. This case report serves as a warning to the surgeon to be aware of such bizarre presentation since the consequences of iatrogenic injury to such structures may be serious.
\end{abstract}

Keywords: Ilioinguinal nerve, Lumbar plexus, Lateral femoral cutaneous nerve.

\section{RESUMEN}

La variabilidad en la formación del nervio ilioinguinal ha sido documentada en la literature especialmente relacionada con el nervio iliohipogástrico. Pero hasta ahora se han documentado muy pocos estudios cadavéricos sobre la variación en las ramas del nervio ilioinguinal. Se presenta un caso que demuestra una aberrancia de su posición anatómica. Aunque el curso del nervio ilioinguinal es bien conocido, ningún estudio ha documentado una variación de su curso en relación con el nervio cutáneo femoral lateral. Este informe de caso sirve como una advertencia al cirujano para que esté al tanto de una presentación tan extraña, ya que las consecuencias de la lesion iatrogénica en tales estructuras pueden ser graves.

Palabras clave: nervio ilioinguinal, plexo lumbar, nervio cutáneo femoral lateral.

\section{INTRODUCTION}

The llioinguinal nerve (IIN) originates from the ventral ramus of first lumbar nerve. It emerges from the lateral border of psoas major, with or just inferior to the iliohypogastric nerve. It passes obliquely across the broad muscles of abdomen before piercing the internal oblique muscleand then traverses the inguinal canal below the spermatic cord (Ndiaye et al., 2010). It emerges with the cord from the superficial inguinal ring to supply the proximal medial skin of the thigh and the skin over the root of the penis and upper part of the scrotum in males, or the skin covering the mons pubis and the adjoining labium majus in female.

Border nerves include the ilioinguinal (IIN), iliohypogastric, and genitofemoral nerves, which supply the skin between the thigh and anterior abdominal wall (Paul and Shastri, 2020). The ilioinguinal nerve and iliohypogastric nerve are likely to get injured during surgeries like appendectomy, inguinal hernia repair, retroperitoneal endoscopic surgeries, bone graft harvesting, breech delivery, prolonged lithotomy position in gynaecological procedures like vaginal hysterectomy (Warner et al., 2000; Izci et al., 2005; Matejcik, 2010).

* Correspondence to: Khizer H A Mookane.
drafroze.homoeo@gmail.com

Received: 13 May, 2021. Revised: 6 June, 2021. Accepted: 11 June, 2021 
This report aims to highlight a rare case of unusual course of ilioinguinal nerve in relation to lateral femoral cutaneous nerve (LFCN), bewaring surgeons to be aware of such bizarre presentation causing iatrogenic injury to above nerves which may have severe consequences.
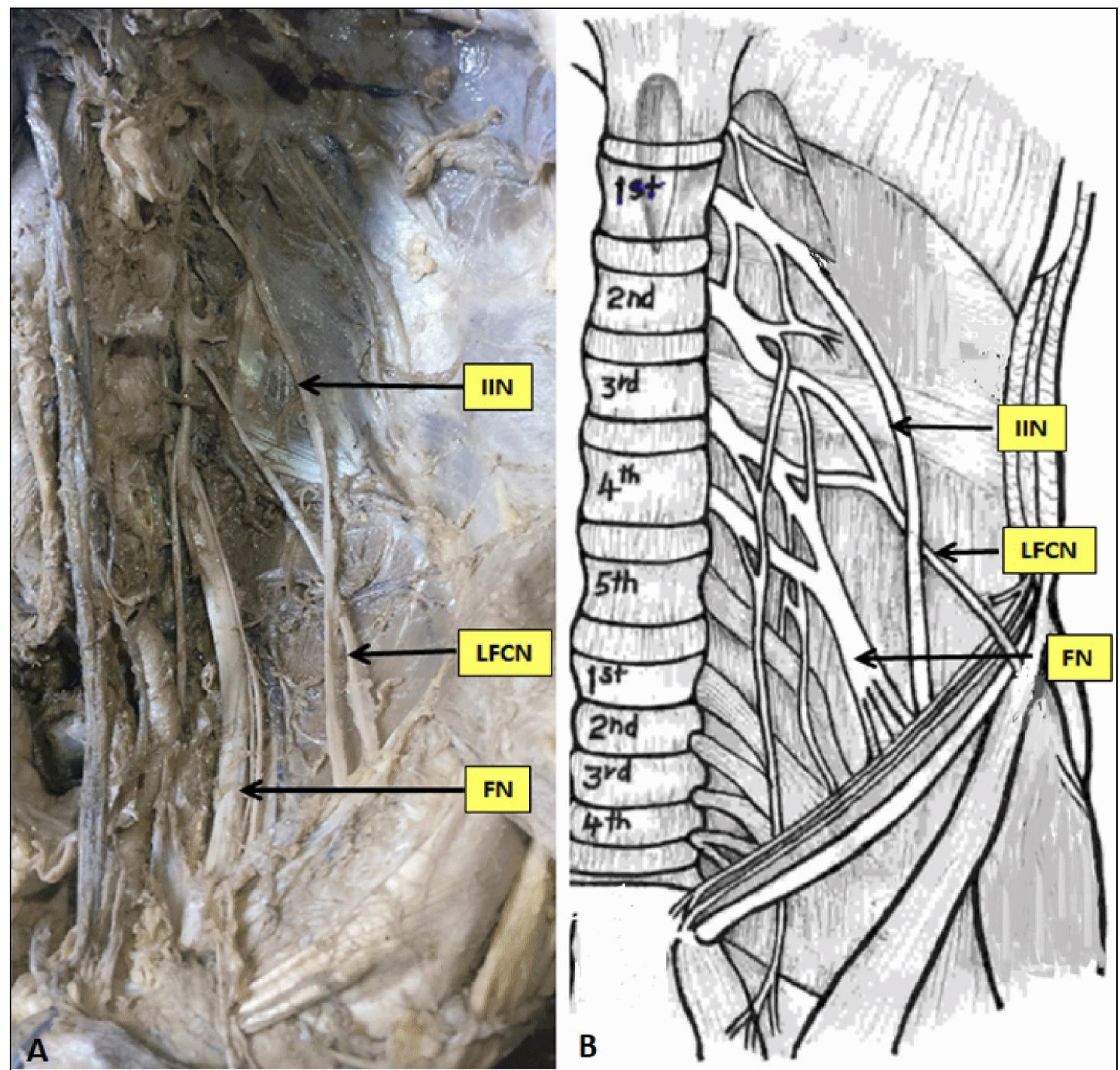

Figure 1A: Left llioinguinal nerve (IIN) crossing over the lateral femoral cutaneous nerve (LFCN). 1B: Diagrammatic representation of the above variation. FN: Femoral Nerve.

\section{CASE REPORT}

An unusual case of a variant course of ilioinguinal nerve (IIN) in relation to lateral femoral cutaneous nerve (LFCN) was detected during a routine dissection of a 68 years old formalin fixed, male cadaver, utilized for dissection class at the Department of Anatomy, MVJ Medical college, Hoskote, Bangalore. Following the steps in Cunnigham's dissection manual, the anterior abdominal was incised. The skin, superficial fascia, muscles of anterior abdominal wall, abdominal organs and retroperitoneum were removed in order to visualize the posterior abdominal wall.

The psoas muscle was removed piecemeal to identify the each branch of lumbar plexus. Usually thellN originates from the $L_{1}$ ventral ramus. It passes obliquely across quadratus lumborum and the upper part of iliacus and enters transverses abdominis near the anterior end of the iliac crest. It pierces internal oblique and supplies it and then traverses the inguinal canal below the spermatic cord. But in the present case, left IIN did not enter the transverse abdominis and directly pierced the internal 
oblique muscle. While traversing in the posterior abdominal wall, it crossed the left lateral femoral cutaneous nerve anteriorlywhich was very unique and has not been reported till date in the literature (Figure 1). The rest of the dissection went smoothly, and the other lumbar plexus branches were found to be normal. The right ilioinguinal nerve showed no variation (Figure 2).

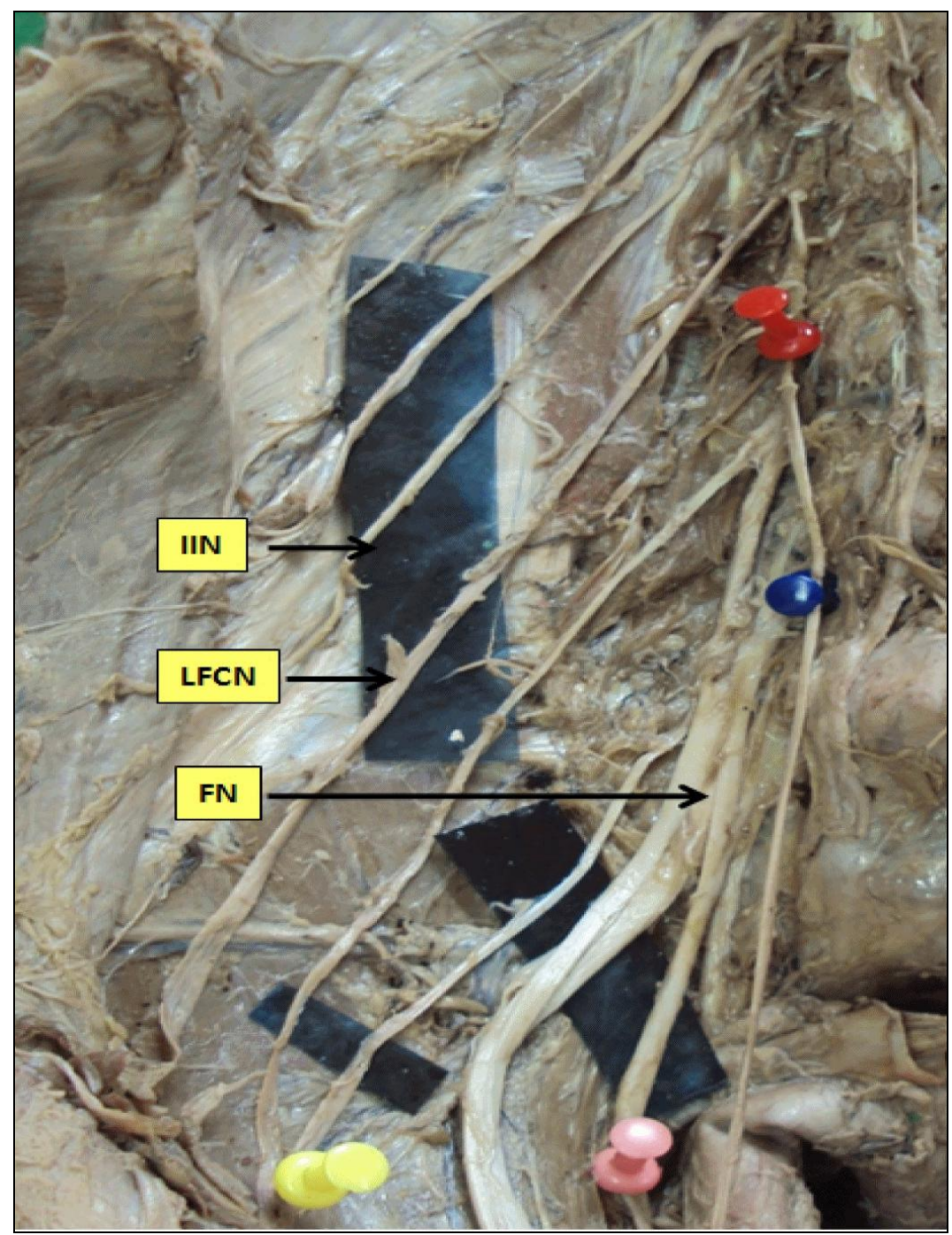

Figure 2: showing the dissection of right side lumbar plexus with no variations.IIN: Ilioinguinal nerve, LFCN: lateral femoral cutaneous nerve, FN: Femoral Nerve.

\section{DISCUSSION}

The previous literature descriptions focus mainly on the variations in the formation of lumbar plexus branches (Matejcik, 2010; Yasarer al., 2014). The ilioinguinal nerve's path deviation is an uncommon occurrence.Few authors have documented aberrant courses of the ilioinguinal nerve throughout its extra-abdominal path that is variation in emergence in the inguinal region and its termination (Papadopoulos and Katritsis, 1981; Ndiaye et al., 2010; Pandhare and Gaiwad,
2013) to a large extent, but its intra-abdominal path remains unexplored.

Das et al. (2014) recorded a single case of variant intra- abdominal course of ilioinguinal nerve and reported that ilioinguinal nerve emerged from the superficial side of the right psoas major muscle which differed from the traditional interpretation of its emergence from the lateral side of the above mentioned muscle.

Normally, the course of LCFN is not related to the IIN, but in our case, it was seen crossing anteriorly by the left IIN which has not been reported in previous literature. 
The most common site of ilioinguinal nerve entrapment is observed in paravertebral region, near iliac crest and the lateral border of rectus abdominis. It may also become entrapped in the inguinal area, and patients who undergo Pfannenstiel incisions or inguinal hernia repairs are more likely to have IIN entrapment somewhere between the ASIS and the pubis (Murinova et al., 2016).

The ilioinguinal nerve entrapment syndrome is mostly caused by its complex inguinal course. However, owing to its variable intra-abdominal course, our study discovered a possible cause of the above mentioned syndrome. The IIN syndrome is characterised by iliac fossa neuralgia radiating to the sensitive territory, which is often associated by paresthesia or altered feeling in the inguinal region and the area supplied by it(Murinova et al., 2016). Likewise LFCN may get sandwiched between the overlying IIN and underlying posterior abdominal wall and the condition may mimic Meralgia Paresthetica.

To conclude, this case is the first of its kind to report a variation in the intra-abdominal course of IIN in relation to LFCN. IIN entrapment is one of the rare differential diagnosis of lower $\mathrm{Gl}$ and genitourinary tract pain and therefore one needs to be aware of the possible sites of entrapment. This case report will alsoadd academic value to the existing literature for surgeons and anesthetists performing nerve block.

\section{Conflict of Interest \\ Nil}

\section{Funding}

Nil

\section{Informed Consent \\ Not Applicable}

\section{Ethical Approval}

It was obtained from the ethical committee of the institution

\section{Contributions}

The authors in this article have made the following contribution: MKHA: Conceptualization, Formal analysis, Investigation, Writing / original draft; AMK: Methodology, Writing / review and editing.

\section{ACKNOWLEDGEMENT}

We sincerely acknowledge the body donors who have selflessly contributed to the resource material of the Department for teaching and research.

\section{REFERENCES}

Das SS, Pangtey B, Mishra S. 2014. A variation in the intra-abdominal course of the ilioinguinal nerve and its clinical implications.OA Anatomy3: 26.

Izci Y, Gurkanlar D, Ozan H, Goul E. 2005. The Morphological Aspects of Lumbar Plexus and Roots. Turkish Neurosurgery 15: 87-92.

Matejcik V. 2010. Anatomical variations of lumbosacral plexus. Surgical and Radiologic Anatomy 32: 409-14.

Murinova N, Krashin D, Trescot AM. 2016. Peripheral nerve entrapments: Clinical diagnosis and management. Peripheral Nerve Entrapments: Clinical Diagnosis and Management, Springer.

Ndiaye A., Diop M, Ndoye JM, Ndiaye A, Mané L, Nazarian S, Dia A. 2010. Emergence and distribution of the ilioinguinal nerve in the inguinal region: Applications to the ilioinguinal anaesthetic block (about 100 dissections). Surgical and Radiologic Anatomy 32: 55-62.

Pandhare S, Gaikwad A. 2013. Anatomical Study of Ilioinguinal Nerve and Its Clinical Correlation. Int J Cur Res Rev 5: 69.

Papadopoulos N, Katritsis ED. 1981. Some observations on the course and relations of the iliohypogastric and ilioinguinal nerves (based on 348 specimens). Anatomischer Anzeiger 149: 357-64.

Paul L, Shastri D. 2019. Anatomical Variations in Formation and Branching Pattern of the Femoral Nerve in lliac Fossa. National Journal of Clinical Anatomy 8: 57.

Warner MA, Warner DO, Harper CM, Schroeder $D R$, Maxson PM. 2000. Lower Extremity Neuropathies Associated with Lithotomy Positions. Anesthesiology 93; 938-80.

Yasar S, Kaya S, Temiz Ç, Tehli O, Kural C, Izci $Y$. 2014. Morphological structure and variations of lumbar plexus in human fetuses. Clinical Anatomy 27: 383-88. 